\title{
PENGARUH FASILITAS DAN KUALITAS PELAYANAN TERHADAP KEPUASAN PENUMPANG DI TERMINAL RAJEKWESI BOJONEGORO
}

\author{
Endang $^{1,2)}$, Laily Nur Cholida ${ }^{3)}$ \\ ${ }^{1}$ Dosen Fakultas Ekonomi Universitas Bojonegoro \\ ${ }^{2}$ Dosen LB Fakultas Teknik Sipil Universitas Bojonegoro \\ ${ }^{3}$ Mahasiswa Fakultas Teknik Sipil Universitas Bojonegoro \\ email: endang106@yahoo.co.id
}

\begin{abstract}
This study aims to determine the effect of simultaneous variables $X_{1}$ (facilities) and $X_{2}$ (service quality) to variable $Y$ (satisfaction) and know the partial influence of variable $X_{1}$ (facility) and $X_{2}$ (service quality) to variable $Y$ (satisfaction). Sampling technique using accidental sampling. Data collection method in this research is using primary data and secondary data. Data were analyzed by using multiple linear regression with the help of SPSS 23. Based on the result of t test data analysis variable $X_{1}$ (facility) and $X_{2}$ (service quality) partially have no significant effect on passenger satisfaction in terminal Rajekwesi Bojonegoro and the result of $F$ test simultaneous variable $X_{I}$ (facility) and $X_{2}$ (service quality) have significant influence to passenger satisfaction in terminal Rajekwesi Bojonegoro.
\end{abstract}

Keywords: facilities, service quality, passenger satisfaction

\section{PENDAHULUAN}

Transportasi mempunyai peranan yang sangat besar dalam kehidupan manusia, dalam perekonomian dan pembangunan, sejak dahulu sampai sekarang dan masa mendatang. Transportasi memiliki fungsi yang strategis, yaitu sebagai fasilitas penunjang (membantu membuka daerah terisolasi, daerah terpencil, daerah tertinggal dan daerah perbatasan). Pentingnya fungsi transportasi dalam perekonomian dan pembangunan, maka kegiatan pelayanan transportasi harus diselenggarakan secara efektif dan efisien, melalui perencanaan, pengaturan dan penyusunan kebijakan (Rahardjo Adisasmita, 2010).

Terminal merupakan salah satu komponen penting dari sistem transportasi, dimana penumpang dan barang masuk dan keluar sebagai tempat awal atau berakhirnya suatu perjalanan. Terminal Rajekwesi Bojonegoro sebelum berada di Jl. Veteran Desa Sukorejo dulunya berada di Jl. Rajekwesi. Sesuai dengan keputusan surat Direktur Jenderal Perhubungan Darat Nomor : KP.801/10/DJPD/2016 tentang operasional terminal tipe A terminal Rajekwesi Bojonegoro telah diambil alih oleh Kementerian Perhubungan Pusat.

Jumlah penumpang di Terminal Rajekwesi Bojonegoro setiap tahun mengalami kenaikan. Hari normal pada tahun 2016 berjumlah 300 penumpang perhari sedangkan pada tahun 2017 sekitar 325 penumpang perhari (Sumber : UPTD Terminal Rajekwesi Bojonegoro Tahun 2017).

Kenaikan penumpang ini dikarenakan semakin banyak masyarakat bojonegoro yang 
melanjutkan pendidikan dan bekerja di luar kota, hal ini yang menyebabkan mereka untuk menggunakan jasa trasnportasi di Terminal Rajekwesi Bojonegoro. Hal ini juga memberi dampak kelonjakan penumpang pada saat momen tertentu seperti libur panjang sekolah dan lebaran, mengalami peningkatan penumpang sekitar 50\% (Sumber : UPTD Terminal Rajekwesi Bojonegoro).

Transportasi merupakan kegiatan jasa pelayanan (service activities) (Rahardjo Adisasmita, 2010). Pada hakekatnya, operasionalisasi terminal Rajekwesi Bojonegoro dapat di pandang sebagai suatu industri jasa, karena menyediakan jasa pelayanan publik yang di dalamnya dilakukan pemungutan biaya berupa retribusi. Dengan semakin meningkatnya jumlah penumpang di terminal Rajekwesi Bojonegoro dari tahun ke tahun dapat berpotensi menimbulkan ketidakseimbangan antara persediaan (supply) dan kebutuhan (demand), yang dapat memicu penurunan kualitas jasa terminal, sehingga berdampak pada penumpang.

Dari latar belakang masalah yang dijelaskan diatas, maka rumusan masalah dalam penelitian adalah : 1) Apakah secara simultan fasilitas dan kualitas pelayanan berpengaruh terhadap kepuasan penumpang di terminal Rajekwesi Bojonegoro?; 2) Apakah secara parsial fasilitas dan kualitas pelayanan berpegaruh terhadap kepuasan penumpang di terminal Rajekwesi Bojonegoro?.

Sesuai dengan latar belakang dan rumusan masalah, maka tujuan penelitian ini adalah: 1) Untuk menganalisa pengaruh simultan fasilitas dan kualitas pelayanan terhadap kepuasan penumpang di terminal Rajekwesi Bojonegoro; 2) Untuk menganalisa pengaruh parsial fasilitas dan kualitas pelayanan terhadap kepuasan penumpang di terminal Rajekwesi Bojonegoro.

\section{METODE PENELITIAN}

Desain dalam penelitian ini menggunakan desain penelitian deskriptif dan asiosiatif. Penelitian ini dilakukan di Terminal Rajekwesi Bojonegoro yang terletak di Jl. Veteran Kabupaten Bojonegoro. Obyek penelitian adalah konsumen pengguna armada bus yang ada di Terminal Rajekwesi Bojonegoro. Populasi adalah wilayah generalisasi yang terdiri dari objek atau subjek yang mempunyai kualitas dan karakteristik tertentu yang ditetapkan oleh peneliti untuk dipelajari dan kemudian ditarik kesimpulannya (Sugiyono,
2010). Sampel adalah bagian dari jumlah dan karakteristik yang dimiliki oleh populasi tersebut (Sugiyono, 2010). Teknik pengambilan sampelnya dengan menggunakan Sampling aksidental.

Metode pengumpulan data dalam penelitian ini adalah data primer dan data skunder. Data primer adalah Sumber data yang secara langsung memberikan data kepada pengumpul data (Sugiono, 2012). Data Skunder adalah data - data yang diperoleh secara tidak langsung termasuk studi literatur berdasarkan hasil penelitian terdahulu yang telah dipublikasikan ataupun data - data yang diperoleh dari berbagai sumber lainnya yang relevan. Sumber data Skunder ini dapat berupa hasil pengolahan lebih lanjut dari data primer yang disajikan dalam bentuk lain atau dari orang lain (Sugiono, 2012).

Instrumen yang digunakan dalam penelitian ini dilakukan dengan menggunakan acuan tabel skala likert 1 sampai dengan 5. Di mana; 1 untuk Sangat Tidak Puas (STP); 2 untuk Tidak Puas (TP); 3 untuk Cukup Puas (CP); 4 untuk Puas (P) dan 5 untuk Sangat Puas (SP).

\section{Teknik Analisa Data}

1. Uji Validitas dan Reliabilitas Kuesioner.

Uji validitas digunakan untuk mengukur sah atau valid tidaknya suatu kuesioner (Ghozali, 2001).

Uji realibilitas dilakukan terhadap item pertanyaan yang dinyatakan valid. Uji ini digunakan untuk mengukur suatu kuesioner yang merupakan indikator dari variabel atau konstruk (Ghozali, 2001)

\section{Analisis Regresi Berganda}

Analisis regresi dipergunakan untuk mengetahui pengaruh atau hubungan antara variabel. Selain itu juga analisis regresi digunakan untuk menguji kebenaran hipotesis yang diajukan dalam penelitian inii. Berikut ini adalah model regresi berganda:

$$
Y=a+b_{1} X_{1}+b_{2} X_{2}+e
$$

Dimana :

$\begin{array}{ll}\mathrm{Y} & =\text { Kepuasan } \\ \mathrm{X}_{1} & =\text { Fasilitas } \\ \mathrm{X}_{2} & =\text { Kualitas Pelayanan } \\ \mathrm{a} & =\text { Konstanta } \\ \mathrm{b}_{1}, \mathrm{~b}_{2} & =\text { Koefisien regresi }\end{array}$


Untuk menilai ketepatan fungsi regresi sampel dalam menaksir nilai aktual dapat diukur dari nilai statistik t, nilai statistik $\mathrm{F}$ dan nilai koefisien determinasi.

\section{Uji T}

Uji $\mathrm{T}$ adalah pengujian koefisien regresi parsial individual yang digunakan untuk mengetahui apakah variabel indepen $\left(\mathrm{X}_{1}\right.$ dan $\left.\mathrm{X}_{2}\right)$ secara individual mempengaruhi variabel dependen (Y). Jika nilai Sig < 0,05 maka variabel independen (X) berpengaruh signifikan terhadap variabel dependen (Y) dan jika nilai $\mathrm{Sig}>0,05$ maka variabel independen (X) tidak berpengaruh signifikan terhadap variabel dependen (Y).

2. Uji F

Uji $F$ adalah pengujian signifikansi persamaan yang digunakan untuk mengetahui seberapa besar pengaruh variabel bebas $\left(\mathrm{X}_{1}\right.$ dan $\left.\mathrm{X}_{2}\right)$ secara simultan terhadap variabel terikat (Y). Jika nilai Sig < 0,05 maka variabel independen (X) berpengaruh signifikan terhadap variabel dependen (Y) dan jika nilai Sig > 0,05 maka variabel independen $(\mathrm{X})$ tidak berpengaruh signifikan terhadap variabel dependen (Y).

3. Koefisien Determinasi

Koefisien determinasi $\left(\mathrm{R}^{2}\right)$ digunakan untuk mengetahui prosentase perubahan variabel dependen (Y) yang disebabkan oleh variabel independen (X). Jika $\mathrm{R}^{2}$ semakin besar, maka prosentase perubahan variabel dependen (Y) yang disebabkan oleh variabel independen (X) semakin tinggi. Jika $\mathrm{R}^{2}$ semakin kecil maka prosentase perubahan variabel dependen $(\mathrm{Y})$ yang disebabkan oleh variabel independen (X) semakin rendah yang disebabkan oleh variabel independen (X) semakin rendah.

\section{HASIL DAN PEMBAHASAN}

Tabel 1. Hasil Uji Validitas

\begin{tabular}{c|c|c|c}
\hline Item & $\begin{array}{c}\text { Item-Total } \\
\text { Correlation }\end{array}$ & $\mathrm{r}$ tabel & Keterangan \\
\hline \multicolumn{4}{c}{ Fasilitas (X1) } \\
\hline X.1.1 & 0,904 & 0,264 & Valid \\
\hline X.1.2 & 0,888 & 0,264 & Valid \\
\hline X1.3 & 0,896 & 0,264 & Valid \\
\hline X.1.4 & 0,917 & 0,264 & Valid \\
\hline$X .1 .5$ & 0,799 & 0,264 & Valid \\
\hline X.1.6 & 0,734 & 0,264 & Valid \\
\hline
\end{tabular}

\begin{tabular}{c|c|c|c}
\hline X.1.7 & 0,590 & 0,264 & Valid \\
\hline X.1.8 & 0,676 & 0,264 & Valid \\
\hline X.1.9 & 0,795 & 0,264 & Valid \\
\hline X.1.10 & 0,773 & 0,264 & Valid \\
\hline Item & $\begin{array}{c}\text { Item-Total } \\
\text { Correlation }\end{array}$ & r tabel & Keterangan \\
\hline \multicolumn{4}{|c}{ Kualitas Pelayanan (X2) } \\
\hline X.2.1 & 0,833 & 0,264 & Valid \\
\hline X.2.2 & 0,839 & 0,264 & Valid \\
\hline X.2.3 & 0,934 & 0,264 & Valid \\
\hline X.2.4 & 0,931 & 0,264 & Valid \\
\hline X.2.5 & 0,816 & 0,264 & Valid \\
\hline \multicolumn{4}{|c}{ Kepuasan (Y) } \\
\hline Y1 & 0,562 & 0,264 & Valid \\
\hline Y 2 & 0,592 & 0,264 & Valid \\
\hline Y 3 & 0,724 & 0,264 & Valid \\
\hline Y 4 & 0,695 & 0,264 & Valid \\
\hline Y 5 & 0,614 & 0,264 & Valid \\
\hline
\end{tabular}

Sumber : Hasil olah data, 2017

Hasil uji validitas menunjukkan bahwa seluruh item pertanyaan dalam kuesioner mempunyai Item-Total Correlation > 0,264 maka pertanyaan tersebut valid.

\section{Uji Reliabilitas}

\section{Tabel 2. Hasil Uji Reliabilitas}

\begin{tabular}{c|l|c|c}
\hline No & \multicolumn{1}{|c|}{ Variabel } & $\begin{array}{c}\text { Cronbach } \\
\text { Alpha }\end{array}$ & Keterangan \\
\hline 1 & Fasilitas (X1) & 0,938 & Reliabel \\
\hline 2 & $\begin{array}{l}\text { Kualitas } \\
\text { Pelayanan (X2) }\end{array}$ & 0,918 & Reliabel \\
\hline 3 & Kepuasan (Y) & 0,628 & Reliabel \\
\hline
\end{tabular}

Sumber : Hasil olah data, 2017

Berdasarkan hasil yang diperoleh dari pengujian reliabilitas instrumen penelitian, karena diperoleh nilai koefisien reliabilitas > 0,60 maka dapat disimpulkan bahwa instrumen penelitian tersebut dinyatakan reliabel.

\section{Analisis Regresi Berganda}

Tabel 3. Hasil Uji Regresi

\begin{tabular}{|c|c|c|c|c|c|}
\hline \multirow[b]{2}{*}{ Model } & \multicolumn{2}{|c|}{$\begin{array}{l}\text { Unstandardized } \\
\text { Coefficients }\end{array}$} & \multirow{2}{*}{$\begin{array}{c}\text { Standardized } \\
\text { Coefficients }\end{array}$} & \multirow[b]{2}{*}{$\mathrm{t}$} & \multirow[b]{2}{*}{ Sig. } \\
\hline & B & $\begin{array}{l}\text { Std. } \\
\text { Error }\end{array}$ & & & \\
\hline 1 (Constant) & 7,302 & 1,797 & & 4,063 &, 000 \\
\hline Fasilitas & 141 & ,084 & ,390 & 1,681 & 101 \\
\hline Kualitas Pelayanan & ,005 & 155 & ,008 & ,035 &, 972 \\
\hline
\end{tabular}

a. Dependent Variable: KEPUASAN

Sumber : Hasil olah data, 2017

Dari hasil uji data yang terdapat pada tabel 3 , diketahui bahwa persamaan regresi untuk hasil penelitian ini adalah sebagai berikut : 
$\mathrm{Y}=7,302+0,141 \mathrm{X}_{1}+0,05 \mathrm{X}_{2}+\mathrm{e}$

Persamaan diatas mengandung maksud bahwa kepuasan dipengaruhi oleh fasilitas dan kualitas pelayanan. Persamaan diatas dapat dijabarkan sebagai berikut :

Konstanta $=7,302$ artinya bahwa nilai konstanta positif menunjukkan pengaruh positif variabel independen (fasilitas dan kualitas pelayanan). Bila variabel independen naik atau berpengaruh dalam satu satuan, maka variabel kepuasan konsumen akan naik atau terpenuhi.

Koefisien $\mathrm{X}_{1}$ sebesar 0,141 artinya bahwa apabila fasilitas, naik satu satuan, maka kepuasan konsumen akan meningkat sebesar 0,141 satuan atau $14,1 \%$.

Koefisien $\mathrm{X}_{2}$ sebesar 0,05 artinya bahwa apabila kualitas pelayanan, naik satu satuan, maka kepuasan konsumen akan meningkat sebesar 0,05 satuan atau $5 \%$.

Selanjutnya untuk menguji hipotesis pertama, yang menyatakan bahwa fasilitas dan kualitas pelayanan secara parsial berpengaruh signifikan terhadap Kepuasan penumpang di terminal Rajekwesi Bojonegoro di gunakan analisis uji t Berdasarkan hasil analisa data dengan menggunakan uji $\mathrm{t}$ diperoleh nilai $\mathrm{t}$ hitung untuk masing-masing variabel sebagai berikut:

1. Nilai t hitung variabel fasilitas $\left(X_{1}\right)$ sebesar 1,681 dengan tingkat signifikan sebesar 0,101 (lebih besar dari 0,05) yang berarti bahwa fasilitas tidak berpengaruh signifikan terhadap kepuasan penumpang di terminal Rajekwesi Bojonegoro.

2. Nilai t hitung variabel kualitas pelayanan $\left(\mathrm{X}_{2}\right)$ sebesar 0,35 dengan tingkat signifikan sebesar 0,972 (lebih besar dari 0,05) yang berarti bahwa kualitas pelayanan tidak berpengaruh signifikan terhadap kepuasan penumpang di terminal Rajekwesi Bojonegoro.

Berdasarkan hasil analisis data, variabel fasilas dan kualitas pelayanan secara parsial tidak berpengaruh signifikan sehingga hipotesis yang menyatakan bahwa fasilitas dan kualitas pelayanan secara parsial berpengaruh signifikan terhadap Kepuasan penumpang di terminal Rajekwesi Bojonegoro, tidak terbukti kebenarannya sehingga hipotesis pertama ditolak.

Pengujian hipotesis kedua yang, menyatakan bahwa secara simultan fasilitas dan kualitas pelayanan berpengaruh signifikan terhadap kepuasan penumpang di terminal Rajekwesi Bojonegoro di gunakan analisis uji $\mathrm{F}$ (Anova) sebagaimana dapat dilihat pada tabel berikut :

\section{Tabel 4. Hasil Uji F (Anova)}

\begin{tabular}{c|c|c|c|c|c}
\hline Model & $\begin{array}{c}\text { Sum of } \\
\text { Squares }\end{array}$ & df & $\begin{array}{c}\text { Mean } \\
\text { Square }\end{array}$ & F & Sig. \\
\hline 1 Regression & 45,745 & 2 & 22,872 & 3,437 &, $043^{\mathrm{b}}$ \\
Residual & 246,230 & 37 & 6,655 & & \\
Total & 291,975 & 39 & & & \\
\hline
\end{tabular}

a. Dependent Variable: KEPUASAN

b. Predictors: (Constant), KUALITASPELAYANAN, FASILITAS

Sumber : Hasil olah data, 2017

Berdasarkan hasil uji $\mathrm{F}$ diperoleh nilai $\mathrm{F}$ hitung sebesar 3,437 dengan tingkat signifikan sebesar 0,043 (lebih kecil dari 0,05) yang berarti bahwa secara simultan fasilitas dan kualitas pelayanan mempunyai pengaruh signifikan terhadap kepuasan penumpang di terminal Rajekwesi Bojonegoro. Dengan demikian dapat dikatakan bahwa hipotesis yang menyatakan bahwa fasilitas dan kualitas pelayanan secara simultan berpengaruh signifikan terhadap kepuasan penumpang di terminal Rajekwesi Bojonegoro terbukti kebenarannya sehingga hipotesis kedua diterima.

Selanjutnya untuk mengetahui konstribusi pengaruh simultan fasilitas dan kualitas pelayanan terhadap kepuasan penumpang di terminal Rajekwesi Bojonegoro digunakan analisis koefisien determinasi sebagaimana dapat dilihat pada tabel berikut :

Tabel 5. Model Summary

\begin{tabular}{c|c|c|c|c}
\hline Model & $\mathrm{R}$ & R Square & $\begin{array}{l}\text { Adjusted } \\
\text { R Square }\end{array}$ & $\begin{array}{c}\text { Std. Error } \\
\text { of the } \\
\text { Estimate }\end{array}$ \\
\hline 1 &, $396^{\mathrm{a}}$ &, 157 &, 111 & 2,57970 \\
\hline
\end{tabular}

Sumber : Hasil olah data, 2017

Berdasarkan hasil perhitungan dengan program SPSS diatas, tampak besarnya koefisien determinasi adalah 0,396 berarti bahwa 39,6\% kepuasan penumpang di terminal Rajekwesi Bojonegoro dapat dijelaskan oleh fasilitas dan kualitas pelayanan sedangkan sisanya sebesar $60,4 \%$ dipengaruhi oleh variabel lain di luar fasilitas dan kualitas pelayanan. 


\section{KESIMPULAN}

Berdasarkan hasil analisis, maka dapat ditarik kesimpulan dalam penelitian ini sebagai berikut : Secara parsial fasilitas dan kualitas pelayanan tidak berpengaruh signifikan terhadap Kepuasan penumpang di terminal Rajekwesi Bojonegoro.

Secara simultan fasilitas dan kualitas pelayanan berpengaruh signifikan terhadap kepuasan penumpang di terminal Rajekwesi Bojonegoro.

\section{Saran}

Dari hasil penelitian yang diperoleh, maka saran yang dapat direkomendasikan adalah:

1. Agar mengupayakan untuk meningkatkan kepuasan penumpang di Terminal Rajekwesi Bojonegoro melalui peningkatan fasilitas dan kualitas pelayanan.

2. Upaya untuk meningkatkan kepuasan penumpang di terminal Rajekwesi Bojonegoro dapat dilakukan menggali variabel-variabel lain selain fasilitas dan kualitas pelayanan karena masih ada $60,4 \%$ kepuasan penumpang yang dipengaruhi variabel lain diluar yang diteliti.

\section{DAFTAR PUSTAKA}

Peraturan Menteri Perhubungan No. PM 132 tahun 2015 tentang Penyelenggaraan Terminal penumpang Angkutan Jalan.

UPTD Terminal Rajekwesi Bojonegoro Tahun 2017.

Direktur Jenderal Perhubungan Darat Nomor : KP.801/10/DJPD/2016 tentang operasional terminal tipe A terminal Rajekwesi Bojonegoro telah diambil alih oleh Kementerian Perhubungan pusat.

Direktorat Jendral Perhubungan Darat No.31 Tahun 1993 tentang terminal transportasi jalan.

Direktorat Jenderal Perhubungan Darat, (1995). Keputusan Menteri Perhubungan Republik Indonesia Tahun 1995 Nomor 31 Pasal 2 Bab II Tentang Terminal Transportasi Jalan. Jakarta : Departemen Perhubungan Darat.

Hannah And Karp, (1991). Jurnal Manajemen Dan Kewirausahaan, 2004, pp. 126127.

Jurnal Hardianawati (2012), yang berjudul Analisis pengaruh kualitas pelayanan jasa terhadap kepuasan masyarakat pengguna Transjakarta Busway

Koridor 2 pada PEMDA DKI Jakarta.

Amri Rifqi Azhari ${ }^{1}$, Nawazirul Lubis ${ }^{2}$ \& Ngatno $^{3}$, Pengaruh Kualitas Pelayanan, Tarif dan Fasilitas Terhadap Kepuasan Penumpang Bus BRT Trans Semarang (Studi Kasus: Penumpang Bus BRT Trans Semarang koridor II).

Sugiyono (2010). Metode Penelitian Pendidikan. Bandung: Alfabeta.

Sugiyono. 2011. Metode Penelitian Kuantitatif Kualitatif dan R\&D. Bandung : Alfabeta

Ghozali. I. 2006. Aplikasi Analisis Multivariate Dengan Program SPSS. Edisi II. Badan Penerbit Universitas Diponegoro. Semarang.

Sujarweni, V. Wiratna (2015). Metodologi Penelitian Bisnis \& Ekonomi. Cetakan Pertama. Yogyakarta: PUSTAKA BARU PRESS.

Adisasmita Rahardjo, Dasar-Dasar Ekonomi Transportasi - Edisi PertamaYogyakarta; Graha Ilmu, 2014

Morlok, Edward, K, 1995. Pengantar Teknik dan Perencanaan Transportasi. Erlangga, Jakarta.

Morlok, E.K. (1991). Pengantar Teknik dan Perencanaan Transportasi Saluran Terbuka. Erlangga. Jakarta.

Tjiptono, Fandy (2000). Total Quality Management. Edisi Ketiga. Yogyakarta: Andi.

Tjiptono, Fandi. 2004. Manajemen Jasa. Andi Ofset.Yogyakarta.

Kotler, Philip \& Susanto, A.B. (2000). Manajemen Pemasaran di Indonesia Analisis, Perencanaan, Implementasi dan Pengendalian. Jakarta: Salemba Empat. 
J u r n a l T e k n i k A

V o l 9 No 2 S e p t e m b e r 2017,911 - 915

ISSN No. 2085 - 0859

Halaman ini sengaja dikosongkan 